\title{
Cumulative incidence, distribution, and determinants of catastrophic health expenditure in Nepal: results from the living standards survey
}

Mamata Ghimire ${ }^{1 *}$ (D) Rakesh Ayer $^{2}$ and Masahide Kondo ${ }^{3}$

\begin{abstract}
Background: Nepal has committed to the global community to achieve universal health coverage by 2030. Nevertheless, Nepal still has a high proportion of out-of-pocket health payment and a limited risk-pooling mechanism. Out-of-pocket payment for the healthcare services could result in catastrophic health expenditure (CHE). Evidence is required to effectively channel the efforts to lower those expenses in order to achieve universal health coverage. However, little is known about CHE and its determinants in a broad national context in Nepal. Therefore, this study was conducted to explore the cumulative incidence, distribution, and determinants of CHE in Nepal.

Methods: Data were obtained from the nationally representative survey, the Nepal Living Standards Survey-third undertaken in 2010/11. Information from 5988 households was used for the analyses. Households were classified as having CHE when their out-of-pocket health payment was greater than or equal to $40 \%$ of their capacity to pay. Remaining households were classified as not having CHE. Logistic regression analyses were used to identify determinants of CHE.

Results: Based on household-weighted sample, the cumulative incidence of CHE was 10.3\% per month in Nepal. This incidence was concentrated in the far-western region and households in the poorer expenditure quartiles. Multivariable logistic regression revealed that households were more likely to face CHE if they; consisted of chronically ill member(s), have a higher burden of acute illness and injuries, have elderly ( $\geq 60$ years) member(s), belonged to the poor expenditure quartile, and were located in the far-western region. In contrast, households were less likely to incur CHE when their household head was educated. Having children ( $\leq 5$ years) in households did not significantly affect catastrophic health expenditure.

Conclusions: This study identified a high cumulative incidence of CHE. CHE was disproportionately concentrated in the poor households and households located in the far-western region. Policy-makers should focus on prioritizing households vulnerable to CHE. Interventions to reduce economic burden of out-of-pocket healthcare payment are imperative to lower incidences of $\mathrm{CHE}$ among those households. Improving literacy rate might also be useful in order to lower CHE and facilitate universal health coverage.
\end{abstract}

Keywords: Catastrophic health expenditure, Incidence, Distribution, Determinants, Nepal

\footnotetext{
* Correspondence: mamata_ghi2003@yahoo.com

${ }^{1}$ Department of Health Care Policy and Management, Graduate School of

Comprehensive Human Sciences, University of Tsukuba, Tennoudai, Tsukuba,

Ibaraki, Japan

Full list of author information is available at the end of the article
} 


\section{Background}

Paying for the healthcare services out-of-pocket (OOP) poses adverse impacts on household economy. Millions of households struggle to finance their healthcare expenses and many of them are driven below the poverty line by such expenses [1, 2]. This struggle for healthcare expenditure is more pronounced in lowincome countries where the health system is poorly funded. In those health systems, measures to protect households financially from healthcare expenditure, such as risk-pooling mechanisms, ${ }^{1}$ are either absent or inadequate [3]. Therefore, in the absence of a financial safety net, healthcare should be purchased by OOP [3]. Any OOP healthcare expenditure that exceeds a specified threshold of household spending is catastrophic and is also referred as catastrophic health expenditure (CHE) $[4,5]$. Financial risk protection from CHE is a key target of universal health coverage (UHC), as mandated by the sustainable development goals (SDGs) [6]. Evidence shows, the financial capacity of households to maintain their basic needs is jeopardized due to CHE [7]. Households incurring CHE are likely to compromise their children's education [8], sell assets [9], and pushed into poverty [10].

The greater episodes of CHE are associated with the higher proportion of OOP payments in the total health expenditure at the health system level [4]. Reversely, OOP payment in health is found to decline when government expenditure in healthcare increases [1]. The share of the government health expenditure is lowest in low-income countries particularly from the South Asia [1]. Despite a call of UHC to protect households from CHE, OOP payment still makes almost half of total health expenditure in those countries [11].

Nepal is a low-income country in South Asia. In Nepal, limited risk-pooling in healthcare makes financial protection no better than most other low-income countries. The health financing system in Nepal does not ensure to protect households from CHE [12]. Despite the commitment of the Nepalese Government (GoN) to achieve UHC by 2030 , nearly $48 \%$ of total health expenditure is still financed by OOP payments [13]. Some of the major public subsidies present in Nepal are treatment subsidies for chronic illness, essential free health care scheme, and cash incentives to pregnant women [14]. However, due to fragmented nature of those subsidies and absence of comprehensive health insurance, necessary financial protection in healthcare is not achieved [12]. Voluntary community-based health insurance programs are present but have low-enrollment rate [15]. Absence of comprehensive health insurance mechanism, high morbidity, reliance on OOP in financing treatment and large share of poverty [16] might have exposed Nepalese households to an increased risk of CHE.
In the past, a few attempts were undertaken to measure the household healthcare expenditure in Nepal [17-20]. Using 1994/95 Nepal Living Standards Survey data, one of the earlier studies examined OOP healthcare payment in Nepal [18]. The study found that financing healthcare by OOP was the major economic burden to the Nepalese households. However, that study did not extend its analyses to CHE. Similarly, a multi-country study also used the same data to report the incidence of CHE in Nepal [17]. That study did not explain the CHE variation by rural/urban or regional context. Other existing studies on CHE in Nepal are either disease-specific [19] or placespecific, that is, conducted in Kathmandu Valley- urban location [20]. Those previous studies may have provided incomplete national scenario on CHE.

We are still unaware of distribution and determinants of CHE in a larger social and economic context. For example, the variation in CHE by administrative regions or by household's economic condition and demographic composition. These contexts are shown to be important by the international studies [7,21-23]. This study aims to contribute to the existing literature by providing answers to these questions by using the latest available nationwide survey data. Policy-wise, knowledge of distribution and determinants is essential to protect the vulnerable households from CHE. It is equally helpful to design the efficient healthcare financing system of the country. Therefore, with the intention to fill the data gap, this study had three objectives: first, to investigate the national cumulative incidence of CHE; second, to measure the distribution of CHE; and final, to examine the determinants of CHE in Nepal.

\section{Methods}

\section{Data source}

This study utilized cross-sectional survey data from the nationally representative Nepal Living Standards Surveythird (NLSS-III). NLSS-III was undertaken by the Central Bureau of Statistics- Nepal (CBS) in 2010/11. This is the latest publicly available Living Standards Survey in Nepal. NLSS-III divided 75 (total) districts of Nepal into 14strata and each stratum was assigned to primary sampling units (PSUs). The PSUs were selected with probability proportional to size, where a number of the household was the measure of size. PSUs were either a ward or a sub-ward in the village development committee. The household was a survey unit.

Data collection for NLSS-III was done over a period of 12 months which was divided into 4 phases to capture the seasonal variation. The survey covered all the administrative regions and geographical belts of the country. Data were collected by a) face-to-face interview, b) observation notes by trained research assistants, and c) anthropometric measurements. Data accuracy of survey was maintained by 
spot-checks and re-checks. A total of 5988 household data collected from 499 PSUs was included in the dataset for the public use. We obtained NLSS-III data from the CBS. All variables used in this study had complete data except for housing rent. Housing rent together with other household expenses was used to compute the total household expenditure. Very small number of household (269 out of 5988 $(0.04 \%))$ had missing data on housing rent. Such missing data was imputed by using a hedonic regression model. The method of this survey is detailed elsewhere [24].

\section{Contents of survey questionnaire}

The NLSS-III household questionnaire contained $21 \mathrm{sec}-$ tions and 9 appendices. We chose five sections among those for this study. First, household roster section was used to gather household demography information. Second, housing section for information on a household's housing expenses. Third, access to facilities section to compute accessibility to the nearest health facility. Fourth, food and non-food expenditure section for the estimation of household consumption expenditure. Final, the health section to analyse treatment costs of illness and injuries. Monetary and in-kind payments made by households on food and non-food items were aggregated to obtain household consumption expenditure as recommended [25]. Recall period was 7 days, 30 days, and 12 months for food expenditure, non-food expenditure, and infrequent non-food expenditure, respectively. We adjusted all data into a 30-days figure as we aimed to measure monthly expenses of households.

In the health section, respondents were asked to report the latest episode of acute illness and injury they suffered during 30 days before the interview. Their responses were coded into 14 categories. Chronic illness was defined as an illness lasting for more than a year. The primary chronic illness suffered and reported by respondents was coded into 13 groups. Any cost, monetary and in-kind, spent for the treatment of chronic illness (in last 12 months) and acute illness and injuries (in last 30 days) was recorded. Incurred expenses by households were recorded in Nepali Rupees (NRs).

\section{Measurement of CHE}

Two major approaches to measure CHE are available $[26,27]$. Firstly, OOP is measured as the proportion of household's total income (say ' $\mathrm{Y}$ '); if OOP/Y exceeds the pre-determined threshold, for example $2.5 \%$ to $15 \%$, the healthcare expenditure is catastrophic [26]. This method is criticised for the equity reason as it uses the same threshold value for both the poor and rich household. The rich households are more likely to overshoot the threshold level without suffering much adverse effect mostly at the higher threshold [27]. Secondly, OOP is measured as the proportion of household's capacity to pay (CTP) put forward by $\mathrm{Xu}$ et al. [4]. CTP = Y-se; where ' $\mathrm{Y}$ ' is the income (or consumption expenditure) used in the first approach. The $s e$ is the basic requirement to maintain a life. A poverty line is used to analyse se. If OOP/CTP is equal to or more than $40 \%$ of CTP healthcare expenditure is catastrophic. We took $40 \%$ cut-off point because this value is recommended by $\mathrm{Xu}$ et al. [4] and is used in previous studies [21-23]. This approach is said to have addressed the equity issue created by the first approach [27]. We used the second approach.

In the second approach, series of steps are involved in the measurement of CHE. These steps were recommended in a multi-country study [4] and extensively used by previous studies [21-23]. The multi-country study was based on the household survey data of 59 countries. Countries from the South Asia region were also involved in that multi-country study. In the same study, the value of $\beta$ (a household scale multiplier) used was 0.56 (95\% CI 0.556-0.572), and was obtained in from a regression equation based on those 59 countries: $\ln ($ food expenditure $)=\ln (\mathrm{k})+\beta \ln ($ household size $)+\Sigma$ yicountry. We used $\beta=0.56$ as the part of the recommendation of the multi-country study.

The steps involved in CHE measurement (see Appendix for detailed explanation) are;

Out-of-pocket $(O O P)$ health payment: direct payment made by households at the point of service use. Payment comprised fee for registration, diagnosis, consultation, surgery; medicine and transportation cost.

Household consumption expenditure (hh_exp): included both monetary and in-kind payment on all goods and services and the money value of the consumption of home-made products.

Food expenditure (foodh): included food expenses and the value of own production by the household.

Equivalent scale (eqsize): calculated as, eqsize $=h h_{s i z} e^{\beta}$, was used (hhsize $=$ household size).

Equivalent food expenditure (eqfoodh) calculated as, eqfoodh $=$ foodh/eqsize

Poverty line $(p l)$ : calculated from among the survey households whose food expenditure was an average of food expenditure of households in $45^{\text {th }}$ and $55^{\text {th }}$ percentile of the total sample. $p l=$ average of eqfoodh where foodh $45<$ eqfoodh $<$ foodh 55

Subsistence spending (se): the minimum requirement to maintain basic life, $\mathrm{se}=\mathrm{pl} *$ eqsize

Capacity to pay (CTP): non-subsistence expenditure by households. For households reporting food expenditure lower than se, CTP was defined as total expenditure minus food expenditure. CTP $=h h_{-}$exp $-s e$ if $s e<=$ foodh; CTP $=$ hh_exp - foodh if $s e>$ foodh

Catastrophic health expenditure (CHE): calculated as, $\mathrm{CHE}=1$ if $\mathrm{OOP} / \mathrm{CTP}>=0.4$, otherwise $\mathrm{CHE}=0$ 


\section{Variables selection Independent variable}

Published studies from low- and middle- income countries offered some guidance in the selection of independent variable in our search for determinants of CHE for this study. Poorer households [22, 28], household demography ( $\leq 5$ year children, $\geq 60$ years elderly) $[29,30]$, urban location [23], female household head [21], chronic illness $[31,32]$ and increased illness episodes [33] were positively associated with CHE. However, households with educated household head were less likely to have $\mathrm{CHE}$ [31]. We also extracted variables such as geographical belts and administrative regions with the intention to explore the distribution of CHE. From north-to-south transect, Nepal has three geographical belts, mountain, hill, and tarai. These belts represent ecological variation. Administratively, Nepal is divided into five development regions- eastern, central, western, mid-western, and far-western from the east to the west. These administrative regions are not proportionately developed. For example, the central region is prosperous than other regions [16]. From a policy perspective, evidence of the regional distribution of $\mathrm{CHE}$ could be of importance to Nepal. Particularly, we were interested to see the variation of $\mathrm{CHE}$ by household demography, illness and injury burden, regional and geographical location, settlement area, and economic condition.

Existing studies have shown that catastrophic health expenditure depends on household's socio-demographic and economic factors, particularly, household demographic composition, literacy and economic status [22, 29-32]. However, it is important to know if those sociodemographic and economic variables interact with each other to produce a biased result. In this study, we introduced three sets of interaction terms to see how those socio-demographic and economic factors mediate with each other and with dependent variable, CHE. 'Household with at least one under 5-years child $\mathrm{x}$ Household reporting acute illness and injuries' was the first interaction term. Similarly, 'Household with at least one 60-years and above elderly x Household reporting chronic illness' was another pair of interaction term. Finally, 'Expenditure quartiles $\mathrm{x}$ Literate household head' was the last pair of interaction term included in the model.

\section{Dependent variable}

CHE was the dependent variable in this study.

\section{Variables extraction and computation}

Variables were extracted at the individual and household level. Raw survey data were used to extract information on individuals reporting chronic illness, acute illness and injuries, seeking care for their acute illness and injuries. A number of individuals reporting both illness was computed. At the household level; gender, education of household head, settlement area, and commute time to the nearest health facility was extracted from the raw data. OOP health expenditure, OOP share of household expenditure, and CTP were computed. Expenditure quartile was ranked by the equivalized per capita household consumption within the sample size. We also calculated household illness ratio for our analysis. The actual household size instead of equivalent size was used for the calculation on illness ratio.

\section{Statistical analyses}

First, we summarized descriptive statistics of extracted and computed variables. Descriptive statistics results were used to see the distribution of the cumulative incidence of CHE among the expenditure quartiles and administrative regions. Second, we assessed the relationship between independent and dependent variables by univariate logistic regression. Finally, we performed multivariable logistic regression. With the exception for ratio of total illness episodes, all variables were taken for univariate logistic regression and then subsequently fed into multivariable logistic regression analysis (34). We saw acute illness and injury ratio and chronic illness ratio of a household separately as we were interested to see their influence on CHE. Household weight was used for the data analysis. All analyses were performed using STATA version 13.1 (College Station, Texas, USA).

\section{Results}

Table 1 gives the summary statistics of extracted and computed variables from the NLSS-III. Around 10.2\% of individuals reported chronic illness while $18.7 \%$ reported acute illness. The mean monthly household expenditure was approximately NRs. 30,000 (414.1 US\$) and the OOP healthcare expenditure was NRs. 1187 (16.4 US\$). The average household size was $4.9 \pm 2.3$. Less than half of households had $\leq 5$ year children, and so were households with elderly members. Almost three-fourth of household heads were male and only one-fourth of the household heads were literate. Geographically, the proportion of households in mountain, hill and tarai belt consisted of $6.9 \%, 47.4 \%$ and $45.7 \%$, respectively. Region-wise, the central region consisted the highest proportion of households $(35.7 \%)$ while the far-western region consisted the least proportion of households (8.5\%). Likewise, $73.1 \%$ of households commuted less than $60 \mathrm{~min}$ to reach the nearest health facility. Of the total households, $43.0 \%$ reported chronic illness, $59.4 \%$ reported acute illness, and $27.2 \%$ households reported both illnesses. The household burden of acute illness and injuries was greater than that of chronic illness. The proportion of households incurring CHE was $10.3 \%$ per month.

Figure 1 is a multi-panel figure and consists of six figures, A to F. The Fig. 1 shows the distribution of financial characteristics, illness, and CHE across expenditure quartiles and 
Table 1 Descriptive statistics of variables extracted and computed from the Nepal Living Standards Survey (NLSS)- Third, 2011

\begin{tabular}{|c|c|c|c|c|c|c|c|}
\hline \multirow[t]{2}{*}{ Variable description } & \multirow[t]{2}{*}{ Observation (N) } & \multicolumn{3}{|l|}{ Weighted } & \multicolumn{3}{|l|}{ Unweighted } \\
\hline & & Proportion & Mean & SD & Proportion & Mean & SD \\
\hline \multicolumn{8}{|l|}{ Extracted Variables } \\
\hline \multicolumn{8}{|l|}{ Individual Level } \\
\hline Individuals reporting chronic illness [yes $=1$; otherwise,0] & 28,474 & $10.2 \%$ & & & $11.4 \%$ & & \\
\hline Individuals reporting acute illness and injuries ${ }^{a}$ [yes $=1$; otherwise, 0 ] & 28,474 & $18.7 \%$ & & & $19.4 \%$ & & \\
\hline $\begin{array}{l}\text { Individual who sought care for their acute illness and injuries } \\
\text { [yes }=1 \text {; otherwise,0] }\end{array}$ & 5518 & $70.7 \%$ & & & $69.3 \%$ & & \\
\hline Individual weights & 28,670 & & & & & 5891.5 & 3717.9 \\
\hline \multicolumn{8}{|l|}{ Household Level } \\
\hline Household expenditure $^{\mathrm{b}}$ (NRs ${ }^{\mathrm{c}}$ ) (in 1000) & 5988 & & 30 & 82 & & 33 & 99 \\
\hline Out of pocket health expenditure (NRs) & 5988 & & 1187 & 4657 & & 1175 & 4743 \\
\hline Household size & 5988 & & 4.9 & 2.3 & & 4.8 & 2.3 \\
\hline Household has under 5-years children [yes $=1$; otherwise,0] & 5988 & $41.7 \%$ & & & $39.9 \%$ & & \\
\hline $\begin{array}{l}\text { Household has elderly ( } 60 \text { years and above) population } \\
\text { [yes }=1 \text {; otherwise, } 0 \text { ] }\end{array}$ & 5988 & $33.2 \%$ & & & $31.8 \%$ & & \\
\hline Household head is male [yes $=1$; otherwise,0] & 5988 & $73.4 \%$ & & & $73.3 \%$ & & \\
\hline Literate household head [yes $=1$; otherwise,0] & 5988 & $22.8 \%$ & & & $25.9 \%$ & & \\
\hline Settlement area is urban [yes $=1$; otherwise,0] & 5988 & $20.9 \%$ & & & $34.9 \%$ & & \\
\hline Geographical belts & 5988 & & & & & & \\
\hline Mountain & & $6.9 \%$ & & & $6.8 \%$ & & \\
\hline Hill & & $47.4 \%$ & & & $53.5 \%$ & & \\
\hline Tarai & & $45.7 \%$ & & & $39.7 \%$ & & \\
\hline Administrative regions & 5988 & & & & & & \\
\hline Eastern & & $23.5 \%$ & & & $21.3 \%$ & & \\
\hline Central & & $35.7 \%$ & & & $38.1 \%$ & & \\
\hline Western & & $20.1 \%$ & & & $19.2 \%$ & & \\
\hline Mid-western & & $12.2 \%$ & & & $12.6 \%$ & & \\
\hline Far-western & & $8.5 \%$ & & & $8.8 \%$ & & \\
\hline $\begin{array}{l}\text { Commute time to the nearest health facility is less than } 1 \mathrm{~h} \\
\text { [yes }=1 \text {; otherwise,0] }\end{array}$ & 5988 & $73.1 \%$ & & & $63.4 \%$ & & \\
\hline Households reporting chronic illness [yes $=1$; otherwise,0] & 5988 & $43.0 \%$ & & & $41.7 \%$ & & \\
\hline Households reporting acute illness and injuries [yes $=1$; otherwise,0] & 5988 & $59.4 \%$ & & & $56.9 \%$ & & \\
\hline Household weights & 5988 & & & & & 964.6 & 348.3 \\
\hline \multicolumn{8}{|l|}{ Computed Variables } \\
\hline \multicolumn{8}{|l|}{ Individual Level } \\
\hline $\begin{array}{l}\text { Individuals reporting both chronic and acute illness [yes }=1 \text {; } \\
\text { otherwise,0] }\end{array}$ & 28,670 & $30.5 \%$ & & & $26.3 \%$ & & \\
\hline \multicolumn{8}{|l|}{ Household Level } \\
\hline Capacity to Pay (NRs) (in 1000) & 5988 & & 18 & 82 & & 22 & 99 \\
\hline OOP share of household expenditure (\%) & 5988 & & 3.9 & 8.0 & & 3.7 & 7.8 \\
\hline OOP share of household capacity to pay & 5988 & & 44.6 & 17.4 & & 42.1 & 17.2 \\
\hline Equivalent household size for each household & 5988 & & 2.4 & 0.6 & & 2.3 & 0.6 \\
\hline $\begin{array}{l}\text { Households reporting both chronic and acute illness [yes }=1 \text {; } \\
\text { otherwise,0] }\end{array}$ & 5988 & $27.2 \%$ & & & $25.6 \%$ & & \\
\hline Number of family members with chronic illness episodes & 5988 & & 0.6 & 0.7 & & 0.5 & 0.7 \\
\hline
\end{tabular}


Table 1 Descriptive statistics of variables extracted and computed from the Nepal Living Standards Survey (NLSS)- Third, 2011 (Continued)

\begin{tabular}{|c|c|c|c|c|c|c|c|}
\hline \multirow[t]{2}{*}{ Variable description } & \multirow[t]{2}{*}{ Observation (N) } & \multicolumn{3}{|l|}{ Weighted } & \multicolumn{3}{|c|}{ Unweighted } \\
\hline & & Proportion & Mean & SD & Proportion & Mean & SD \\
\hline Number of family members reporting acute illness and injuries episodes & 5988 & & 1.0 & 1.1 & & 0.9 & 1.1 \\
\hline Ratio of acute illness and injuries episodes to household size & 5988 & & 0.2 & 0.2 & & 0.2 & 0.2 \\
\hline Ratio of chronic illness episodes to household size & 5988 & & 0.1 & 0.2 & & 0.1 & 0.2 \\
\hline Ratio of total illness episodes to household size & 5988 & & 0.4 & 0.4 & & 0.4 & 0.4 \\
\hline Expenditure quartiles $^{d}$ & 5988 & & & & & & \\
\hline 1 & & $25.0 \%$ & & & $22.6 \%$ & & \\
\hline 2 & & $25.0 \%$ & & & $22.8 \%$ & & \\
\hline 3 & & $25.0 \%$ & & & $24.9 \%$ & & \\
\hline 4 & & $25.0 \%$ & & & $29.7 \%$ & & \\
\hline Households with CHE ( $>=40 \%$ of CTP) [yes $=1$; otherwise, 0$]^{\mathrm{e}}$ & 5988 & $10.3 \%$ & & & $9.1 \%$ & & \\
\hline
\end{tabular}

${ }^{a}$ recall period was 30 days and only one episode was reported. ${ }^{b}$ expenditures were adjusted in a monthly figure. ${ }^{c}$ in February 2011,1 US\$ was approximately equal to $72.45 \mathrm{NRs} .{ }^{\mathrm{d}}$ quartile 1 represents the poorest while 4 represents the wealthiest. ${ }^{\mathrm{e}}$ Cumulative incidence of catastrophic health expenditure (CHE) per month

administrative regions. Figure A shows that the increasing order of household expenditure, CTP, and OOP health expenditure as we move from the 1st quartile (poorest) to the 4th quartile (wealthiest). However, CHE was highest (15.8) in the 2nd quartile. Figure $B$ demonstrates that the farwestern region had the lowest CTP and OOP but the highest $\mathrm{CHE}$ (12.8). Figure $\mathrm{C}$ shows that the households in the 2nd quartile and 4th quartile reported the highest percentage of acute illness (61.2) and chronic illness (47.3) respectively. Figure D presents regional distribution of illness. Households in the eastern and mid-western regions reported a higher proportion of illness and injuries. Figure $\mathrm{E}$ further shows that the far-western and mid-western regions mostly consisted of households belonging to the poor quartiles in comparison to other regions. Figure F shows the proportion of reported household illness with and without CHE. Of the total, $75.1 \%$ of households reported illness and $10.3 \%$ of those illness episodes were with CHE. Similarly, for the households reporting chronic illness episodes only, 1.5\% experienced $\mathrm{CHE}$. This proportion was higher (3.8\%) in case of households reporting acute illness and injuries. Likewise, $5.0 \%$ of episodes were with $\mathrm{CHE}$ in the households reporting the double burden of illness.

Table 2 shows univariate logistic regression of independent variable against dependent variable, CHE. Households having elderly member(s) and children were vulnerable to CHE. However, households in urban and households with educated heads were less likely to incur CHE. Households reporting chronic illness, acute illness and injuries, and a higher ratio of illnesses, in the hilly belt, in 1st and 2nd quartiles, were more likely to suffer from $\mathrm{CHE}$. All variables from univariate logistic regression were fed into multivariable logistic regression.

Table 3 presents the determinants of CHE. Model 1 is the multivariable logistic regression without any interaction terms. Model 1 shows that households with elderly members (33.2\%) were more likely to experience CHE. Whereas, households with a literate household head (22.8\%) were less likely to incur CHE. Households with chronic illness, acute illness were all highly likely to face $\mathrm{CHE}$. The acute illness burden of a household was catastrophic (OR $=2.33$, 95\% $\mathrm{CI}=1.48,3.67)$ than the chronic illness burden. Households with the poor economic condition incurred $\mathrm{CHE}$. The findings revealed that households in the far-western region were vulnerable to $\mathrm{CHE}(\mathrm{OR}=1.46, \mathrm{CI}=1.02,2.11)$ in comparison to households in the central region. Model 2 in Table 3 introduces three sets in interaction terms. None of the interaction terms were statistically significant. Selected interaction terms did not significantly influence either independent variables used in this study or their main effect on dependent variable as presented in model 1.

Multicollinearity was not identified in multivariable logistic regression model 1 and model 2 . This conclusion was reached after calculating variance inflation factor (VIF). The mean VIF was 2.01 for model 1 and 2.38 for model 2. None of the variables had variance inflation factor greater than 10.0, the recommended value [34]. Besides that, goodness of fit test the model 1 was $p=$ 0.102 and model 2 was $p=0.106$. We checked this by Hosmer- Lemeshow goodness of fit test. The diagnostic plots of the model are provided in Additional file 1.

\section{Discussion}

This study was based on nationally representative data and the findings are important as they provide a complete national scenario on CHE in Nepal. The study answers its three research questions. First, the cumulative incidence of CHE was $10.3 \%$ per month at the national level in Nepal. Second, CHE was distributed unevenly across expenditure quartiles and administrative regions. Third, 

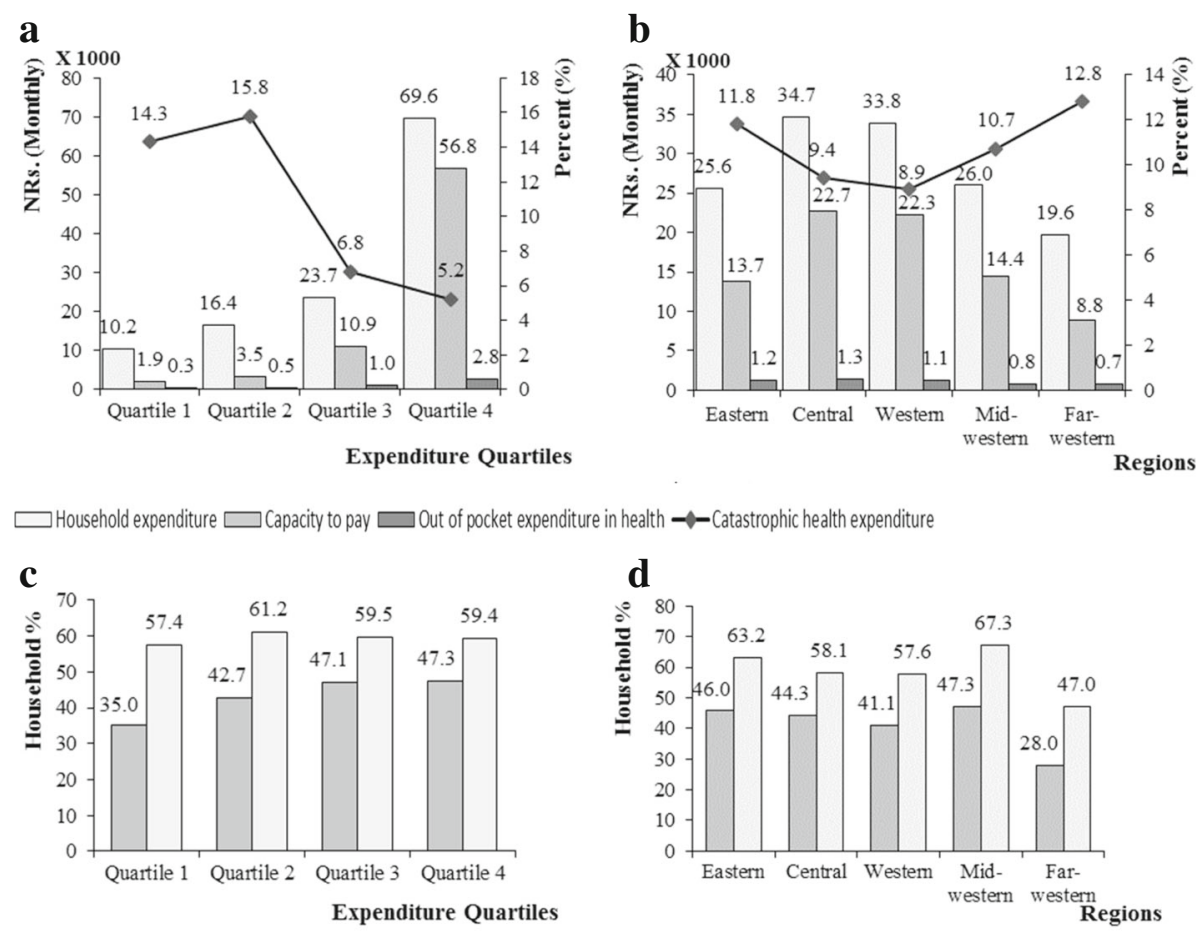

口Households reporting chronic illness $\quad$ पHouseholds reporting acute illness and injuries
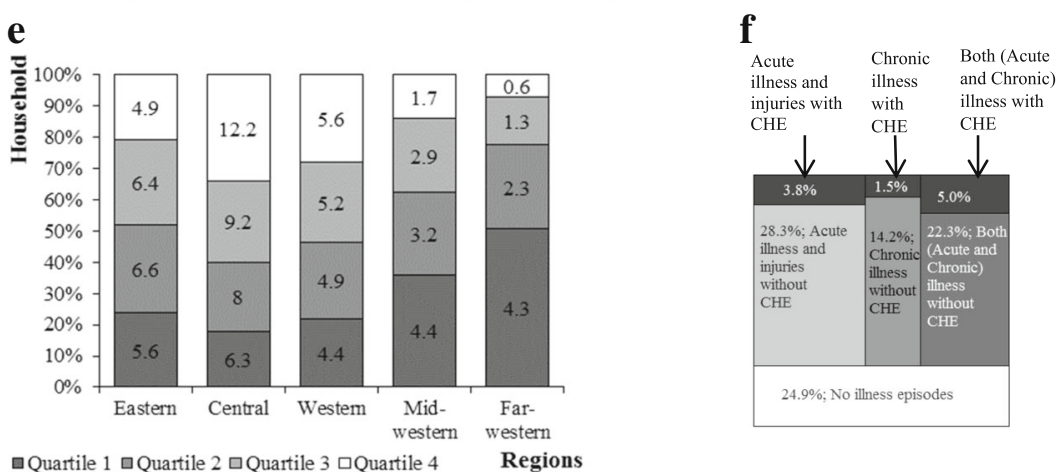

Fig. 1 Distribution of financial characteristics, illness, and CHE across expenditure quartiles and administrative regions in Nepal, 2011. This figure consists of six sub-figures, (a-f), to reflect the nationwide distribution of CHE. Each sub-figure has unique title. A. Distribution of financial characteristics and CHE across expenditure quartiles. $\mathbf{b}$ Distribution of financial characteristics and CHE across administrative regions. $\mathbf{c}$ Distribution of illnesses across expenditure quartiles. d Distribution of illnesses across administrative regions. e Distribution of expenditure quartiles across administrative regions. $\mathbf{f}$ National picture of reported household illness episodes with and without CHE

CHE was determined by household illness, economic condition, and location. For instance, households with chronically ill member(s), higher episodes of acute illness, located in the poorer quartiles and the far-western region were more likely to face CHE.

The national cumulative incidence of CHE was 10.3\% per month at a threshold of $40 \%$ or greater household's CTP. Chronic illness was reported by $43.0 \%$ households. Similarly, the incidence of acute illness and injury was 59.4\%. In the poorly developed risk-pooling system, seeking treatment to this staggering burden of illness might have imposed high healthcare cost to households. Evidence shows that risk-pooling mechanism such as insurance offers financial protection against CHE [35]. UHC targets to achieve $100 \%$ financial protection against CHE [6]. In this context, $10.3 \%$ cumulative incidence of $\mathrm{CHE}$ per month is high and needs an immediate attention.

CHE was distributed disproportionately in the poor quartiles and regions. Across expenditure quartile, $\mathrm{CHE}$ was concentrated in the 1st and 2nd quartiles in comparison to others. This concentration could be explained by household CTP. The 4th quartile had a higher average CTP, almost 28 times, as compared to the 1st. Due to low CTP, OOP payment for illness carried potential to be the catastrophic expenditure to those households. A similar trend was shown by previous studies [21, 23]. Region- 
Table 2 Univariate logistic regression of household characteristics with $\mathrm{CHE}(N=5988)$

\begin{tabular}{|c|c|c|}
\hline \multirow[t]{2}{*}{ Household Characteristics } & \multicolumn{2}{|l|}{$\mathrm{CHE}$} \\
\hline & OR $(95 \% \mathrm{Cl})$ & $p$-value \\
\hline Equivalent household size & $0.97(0.83-1.14)$ & 0.736 \\
\hline $\begin{array}{l}\text { Household has under } 5 \text {-years children } \\
\text { [yes }=1 \text {; otherwise,0] }\end{array}$ & $1.22(1.00-1.49)$ & 0.048 \\
\hline $\begin{array}{l}\text { Household has elderly ( } 60 \text { years and } \\
\text { above) population [yes }=1 \text {; otherwise,0] }\end{array}$ & $1.60(1.34-1.92)$ & $<0.001$ \\
\hline $\begin{array}{l}\text { Household head is male } \\
\text { [yes }=1 \text {; otherwise, } 0 \text { ] }\end{array}$ & $0.90(0.72-1.11)$ & 0.334 \\
\hline $\begin{array}{l}\text { Settlement area is urban } \\
\text { [yes }=1 \text {; otherwise, } 0 \text { ] }\end{array}$ & $0.46(0.35-0.60)$ & $<0.001$ \\
\hline $\begin{array}{l}\text { Literate household head } \\
\text { [yes }=1 \text {; otherwise,0] }\end{array}$ & $0.51(0.39-0.68)$ & $<0.001$ \\
\hline $\begin{array}{l}\text { Commute time to the nearest health facility } \\
\text { is less than } 1 \mathrm{~h} \text { [yes }=1 \text {; otherwise,0] }\end{array}$ & $1.85(1.46-2.34)$ & $<0.001$ \\
\hline $\begin{array}{l}\text { Households reporting at least one member } \\
\text { with chronic illness [yes }=1 \text {; otherwise, } 0 \text { ] }\end{array}$ & $2.48(2.04-3.03)$ & $<0.001$ \\
\hline $\begin{array}{l}\text { Households reporting at least one member } \\
\text { with acute illness and injuries } \\
\text { [yes }=1 \text {; otherwise,0] }\end{array}$ & $4.68(3.64-6.01)$ & $<0.001$ \\
\hline Chronic illness ratio & $4.14(2.89-5.77)$ & $<0.001$ \\
\hline Acute illness and injuries ratio & $6.49(4.94-8.52)$ & $<0.001$ \\
\hline \multicolumn{3}{|l|}{ Expenditure quartiles } \\
\hline 1 & $3.02(2.24-4.08)$ & $<0.001$ \\
\hline 2 & $3.40(2.59-4.47)$ & $<0.001$ \\
\hline 3 & $1.16(0.52-1.64)$ & 0.374 \\
\hline 4 & 1.00 & \\
\hline \multicolumn{3}{|l|}{ Geographical belts } \\
\hline Mountain & 1.00 & \\
\hline Hill & $0.66(0.45-0.98)$ & 0.040 \\
\hline Tarai & $0.98(0.67-1.44)$ & 0.925 \\
\hline \multicolumn{3}{|l|}{ Administrative regions } \\
\hline Central & 1.00 & \\
\hline Eastern & $1.28(0.97-1.69)$ & 0.075 \\
\hline Western & $0.94(0.69-1.29)$ & 0.718 \\
\hline Mid-western & $1.14(0.83-1.57)$ & 0.398 \\
\hline Far-western & $1.40(0.99-2.00)$ & 0.055 \\
\hline
\end{tabular}

wise, the highest incidence of CHE was seen in the farwestern followed by the eastern. However, households in the far-western region were hit hardest by CHE as $77.6 \%$ of households in the far-western belonged to the poorer quartiles compared to $51.9 \%$ in the eastern region.

Illness burden in household determined CHE in Nepal. Households with chronically ill member(s) were 2.4 times more likely to suffer CHE. Chronic illness often needs continuous treatments and consultations. This puts households in constant pressure to finance such treatment which invites financial ruins. The result supports findings from previous studies [28, 33]. This reason also offers the explanation on the increased risk of CHE among households with elderly member(s). Households reporting at least one member with acute illness and injuries were 3.4 times more likely to incur CHE. In fact, households with the increased burden of acute illness and injury episodes were likely to face $\mathrm{CHE}$ by 2.3 times compared to those who did not have such burden. The treatment cost could easily exceed the CTP of households, especially of households with the poor economic condition, when they unexpectedly purchase healthcare by OOP. The household illness episode was considered in this study. This consideration holds explanation that the cost of each illness episode ultimately falls into the household healthcare expenditure as pointed by Sauerborn et al. [36].

The household economic condition was another key driver of CHE in Nepal. Households located in 1st and 2nd quartiles were almost equally vulnerable to CHE compared to the 4th quartile. Households from 4th quartile reported not only more episodes of illness but also greater CTP for their illness. However, even smaller healthcare expenditure was catastrophic to the poor households. This finding is consistent with earlier studies [28].

Households in the far-western region were more likely to incur CHE. This unique finding for Nepal holds two possible explanations. First, the far-western region has low development indicators in comparison to other regions [16]. In this study, more than three-quarters of households in the far-western region belonged to the poor quartile. This shows the economic status of the farwestern region is not strong. This finding with some variation can be compared to the finding from the Chinese study [21]. Second, as this region is near to the Indian border, people might often commute to the Indian side for their treatment. This practice could potentially increase OOP healthcare expenditure of their households.

Households with educated household head were 27\% less likely to incur CHE while households with children had no significant effect on CHE in Nepal. This study showed that households with literate head were less likely to incur CHE. Two reasons could explain this finding. First, household with literate household head might be aware of their health behaviour. Grossman theorizes that education brings health awareness [37]. Educated household heads are more cautious on their own health behaviour and that of their family members. In the long run, such households are likely to practice preventive behaviour to avoid illness which would further prevent catastrophic expenses in healthcare. This finding is consistent with a Tanzanian study [32]. Second, improved literacy could also lead to greater income generation. Improved income potentially leads to improved health as described in the published literature [38]. Nonetheless, households 
Table 3 Determinants of CHE in Nepal, 2011

\begin{tabular}{|c|c|c|}
\hline \multirow[t]{2}{*}{ Household Characteristics } & Model 1 & Model 2 \\
\hline & OR $(95 \% \mathrm{Cl})$ & OR $(95 \% \mathrm{Cl})$ \\
\hline Equivalent household size & $0.87(0.71-1.07)$ & $0.88(0.72-1.08)$ \\
\hline $\begin{array}{l}\text { Household has under } \\
5 \text {-years children } \\
\text { [yes }=1 \text {; otherwise,0] }\end{array}$ & $1.11(0.87-1.41)$ & $0.87(0.54-1.41)$ \\
\hline $\begin{array}{l}\text { Household has elderly ( } 60 \text { years } \\
\text { and above) population } \\
\text { [yes }=1 \text {; otherwise,0] }\end{array}$ & $1.37(1.13-1.66)^{* *}$ & $1.34(0.96-1.87)^{*}$ \\
\hline $\begin{array}{l}\text { Household head is male } \\
\text { [yes }=1 \text {; otherwise, } 0 \text { ] }\end{array}$ & $1.00(0.79-1.27)$ & $1.00(0.79-1.27)$ \\
\hline $\begin{array}{l}\text { Settlement area is Urban } \\
\text { [yes }=1 \text {; otherwise,0] }\end{array}$ & $0.79(0.58-1.06)$ & $0.79(0.58-1.06)$ \\
\hline $\begin{array}{l}\text { Literate household head } \\
\text { [yes = 1; otherwise,0] }\end{array}$ & $0.73(0.54-1.00)^{*}$ & $0.61(0.34-1.10)^{*}$ \\
\hline $\begin{array}{l}\text { Commute time the nearest health } \\
\text { facility less than } 1 \mathrm{~h} \\
\text { [yes }=1 \text {; otherwise, } 0 \text { ] }\end{array}$ & 1.05(0.79-1.38) & $1.03(0.78-1.36)$ \\
\hline $\begin{array}{l}\text { Households having member } \\
\text { with chronic illness } \\
\text { [yes }=1 \text {; otherwise,0] }\end{array}$ & $2.40(1.78-3.24)^{* * *}$ & $2.37(1.72-3.29)^{* * *}$ \\
\hline $\begin{array}{l}\text { Households having member } \\
\text { with acute illness } \\
\text { [yes = 1; otherwise,0] }\end{array}$ & $3.41(2.53-4.58)^{* * *}$ & $3.07(2.15-4.37)^{* * *}$ \\
\hline Acute illness ratio & $2.33(1.48-3.67)^{* * *}$ & $2.39(1.52-3.76)^{* * *}$ \\
\hline Chronic illness ratio & $1.27(0.65-2.48)$ & $1.25(0.64-2.44)$ \\
\hline \multicolumn{3}{|l|}{ Expenditure quartiles } \\
\hline 1 & $3.15(2.21-4.49)^{* * *}$ & $2.91(1.98-4.27)^{* * *}$ \\
\hline 2 & $3.29(2.42-4.49)^{* * *}$ & $3.14(2.23-4.45)^{* * *}$ \\
\hline 3 & $1.05(0.73-1.52)$ & $1.07(0.71-1.59)$ \\
\hline 4 & 1.00 & 1.00 \\
\hline \multicolumn{3}{|l|}{ Geographical belts } \\
\hline Mountain & 1.00 & 1.00 \\
\hline Hill & $0.92(0.62-1.38)$ & $0.92(0.62-1.38)$ \\
\hline Tarai & $1.21(0.81-1.80)$ & $1.21(0.81-1.80)$ \\
\hline \multicolumn{3}{|l|}{ Administrative regions } \\
\hline Central & 1.00 & 1.00 \\
\hline Eastern & $1.02(0.76-1.37)$ & $1.03(0.77-1.37)$ \\
\hline Western & $0.93(0.68-1.27)$ & $0.93(0.68-1.27)$ \\
\hline Mid-western & $0.86(0.63-1.16)$ & $0.86(0.63-1.16)$ \\
\hline Far-western & $1.46(1.02-2.11)^{*}$ & $1.47(1.02-2.11)^{*}$ \\
\hline
\end{tabular}

Interaction terms

Household with at least one under 5-years child $x$ Household reporting acute illness and injuries

Household with at least one 60-years and above elderly $x$ Household reporting chronic illness

Expenditure quartiles $x$ Literate household head

Poorest (1) x Yes

$1.89(0.02-4.38)$

Quartile $2 \times$ Yes
Table 3 Determinants of CHE in Nepal, 2011 (Continued)

\begin{tabular}{lll}
\hline Household Characteristics & $\begin{array}{l}\text { Model 1 } \\
\text { OR }(95 \% \mathrm{Cl})\end{array}$ & $\begin{array}{l}\text { Model } 2 \\
\text { OR }(95 \% \mathrm{Cl})\end{array}$ \\
\hline Quartile $3 \times$ Yes & $0.83(0.34-2.06)$ \\
Wealthiest $(4) \times$ Yes & 1.00 \\
\hline Model 1: without interaction terms. $\mathrm{N}=5988, \mathrm{LR} \mathrm{X}^{2}=599.1$, Pseudo $\mathrm{R}^{2}=0.1524$, \\
Mean VIF $=2.01$. Model 2: with interaction terms. $N=5988, \mathrm{LR} \mathrm{X}^{2}=564.6$, Pseudo \\
$\mathrm{R}^{2}=0.1539$, Mean VIF $=2.38$ \\
${ }^{*} p<0.10$ \\
${ }^{* *} p<0.01$ \\
${ }^{* * *} p<0.001$
\end{tabular}

with children ( $\leq 5$ years) had no significant association with CHE. Maternal-and-child health program is a priority program of the GoN. Services like immunization, treatment of childhood illness are provided free of cost [14]. Although the effects of maternal-and-child health programs were not analysed, we suppose, those free services might have contributed in reducing childhood related healthcare expenditure.

\section{Limitations of the study}

The findings of this study should be considered in the context of a few major shortcomings. First, though limited, the presence of public subsidies cannot be denied in Nepal. However, the survey data used had no variables reflecting the utilization of those schemes. Second, strategies adopted by households to cope $\mathrm{CHE}$ was not analysed. A qualitative study is preferred to explore household coping strategies. This study warrants future studies to explore the strategies adopted by households to cope CHE. Third, although access to the closest health facility was seen, no further analysis of healthcare delivery side was done because of the limited variables in the NLSS data. Finally, the competing approach and threshold to measure CHE might yield different values of CHE. However, this study applied the standard method to measure CHE.

\section{Policy implications and recommendations}

The commitment of the GoN to global community to achieve UHC by 2030 against the backdrop of limited fiscal space is a daunting challenge [13]. This study intends to bring CHE in the forefront of policy discussion as Nepal aims to introduce social health security scheme (SHSS) (technically called Social Health Insurance) to attain UHC [14]. In the long run, increasing the government's share to finance healthcare is considered as obvious policy [35, 39]. Meanwhile, findings of this study can help locate the vulnerable households to lower CHE in Nepal. In light of its findings, this study recommends to: a) prioritize groups and regions strategically when introducing any risk-pooling mechanisms; and b) intensify interventions to improve literacy rate.

This study clearly showed that households in poorer quartiles and regions suffered from CHE. For instance, 
households in the far-west regions were from the poor quartile and were very likely to face CHE. So, this study recommends prioritizing the vulnerable households and regions. The far-western region could be selected as a pilot region for the SHSS. Also, unexpected expenditure for treating acute illness and injuries had more tendency to be catastrophic to the household in Nepal. Therefore, management of such morbidities should be the goals of policymakers. Management could be done through improving general literacy rate in the country. This leads to our next recommendation: tailored interventions to improve literacy rate could be beneficial to manage acute illness and injuries in Nepal. An Indian study also reported that increasing literacy, especially among female member of a household, was advantageous in reducing catastrophic OOP health expenditure [40]. Interventions to improve literacy could be helpful in managing illnesses and lowering CHE in Nepal.

\section{Conclusions}

The cumulative incidence rate of $\mathrm{CHE}$ was $10.3 \%$ per month in Nepal. CHE was concentrated in the poorer quartiles and far-western region. Furthermore, this study demonstrated that increased illness episodes in a household triggered CHE. CHE was also influenced by household's regional location, economic status, chronic illness, acute illness, and education of household head. Findings of this study underscore the importance of incorporating efforts to effectively prioritize the vulnerable households and improve literacy with the current endeavours of the GoN. UHC is a health policy priority, globally. Policy recommendations offered by this study could be of use to lower the CHE and facilitate UHC in Nepal and countries with similar socio-economic context.

\section{Endnotes}

${ }^{1}$ Risk pooling mechanism in health system is a function which ensures that the risk related to financing health care interventions is shared by all the members of the pool. The major objective of risk pooling is to distribute the financial risk associated with health care interventions for which there is uncertain need $[2,3]$.

\section{Appendix}

Equations used in the measurement of CHE

Main variables:

OOP $=$ Out-of-pocket health expenditure

hh_exp $=$ Household consumption expenditure

food_h $=$ Food expenditure

eqsize $=$ Equivalent household size

hhsize $=$ Household size

eqfoodh $=$ Equivalent food expenditure

$\mathrm{pl}=$ Poverty line

$\mathrm{se}=$ Subsistence spending

poorh $=$ poor household
CTP $=$ Capacity to pay

$\mathrm{CHE}=$ Catastrophic health expenditure

Steps:

Generate the equivalent household size for each household as

eqsize $=$ hhsize $^{\wedge} \beta$ [The value of $\beta$ (which is a household scale multiplier) used was 0.56 [4]. The value of 0.56 is obtained in from a regression equation based on 59 countries: $\quad \ln ($ food_h $)=\ln (\mathrm{k})+\beta \quad \ln ($ hhsize $)+\Sigma$ ricountry]

Estimate equivalent food expenditure (eqfoodh) as eqfoodh $=$ foodh/eqsize

Identify the food expenditure shares of total household expenditure that are at the 45 th and 55 th percentile across the whole sample, name these two variables as foodh 45 and foodh55.We used household weight (wh) in the percentile calculation. Calculate the average of food expenditure of the households in the 45th to 55th percentile range to obtain the subsistence expenditure per (equivalent) capita, which is also the poverty line (pl).

$$
\begin{aligned}
\mathrm{pl}= & \sum 45 \text { th to } 55 \mathrm{th}^{*}\left(\text { eqfoodh } / \sum \text { wh }(45 \text { th to } 55 \text { th })\right) \\
& \text { where foodh } 45<\text { eqfoodh }<\text { foodh } 55
\end{aligned}
$$

Calculate Subsistence spending as, $\mathrm{se}=\mathrm{pl}$ "eqsize

\{A household is regarded as poor (poorh) when its total household expenditure is smaller than its subsistence spending. Poorh $=1$ if hh_exp $<$ se, otherwise Poorh $=0\}$

Next, calculate capacity to pay (CTP) as,

$$
\begin{aligned}
\mathrm{CTP} & =\mathrm{hh}_{-} \text {exp-se if se }<=\text { foodh } \text { CTP } \\
& =\mathrm{hh}_{-} \text {exp-foodh if se }>\text { foodh }
\end{aligned}
$$

Finally, calculate catastrophic health expenditure (CHE) as,

$$
\mathrm{CHE}=1 \text { if OOP } / \mathrm{CTP}>=0.4 \text {, otherwise } \mathrm{CHE}=0
$$

\section{Additional file}

Additional file 1: Plots demonstrating the diagnostic check of the model 1. Figure S1. (A-F): Plots demonstrating the diagnostic check of the model 1. The additional file consists six graphs, A-F. A: Plot of Pearson residuals versus the predicted probability of catastrophic health expenditure. B: Plot of Pearson residuals versus household number. C: Plot of deviance residuals versus the predicted probability of catastrophic health expenditure. D: Plot of deviance residuals versus household number. E: Plot of leverage versus the predicted probability of catastrophic health expenditure. F: Plot of leverage versus household number. (DOCX $943 \mathrm{~kb}$ )

\section{Abbreviations}

CBS: Central Bureau of Statistics- Nepal; CHE: Catastrophic health expenditure; Cl: Confidence interval; CTP: Capacity to pay; GoN: Government of Nepal; LR: Likelihood ratio; NLSS-III: Nepal living standards survey- third; NRs: Nepali Rupees; OOP: Out-of-pocket; OR: Odds ratio; p: p-value;

PSU: Primary sampling unit; SDG: Sustainable development goal; SHSS: Social 
health security scheme; UHC: Universal health coverage; VIF: Variance inflation factor; $X^{2}$ : Chi square

\section{Acknowledgements}

The authors would like to thank the Central Bureau of Statistics, Nepal for providing us the data. We are grateful to Dr. Shiva Raj Adhikari and Lee Hayes for their constructive advice in this paper.

\section{Funding}

Not applicable.

\section{Availability of data and materials}

The data and materials used in the study are public available and can be accessed from the following website http://microdata.worldbank.org/index.php/catalog/ 1000/study-description

\section{Authors' contributions}

MG conceptualized the study design, performed statistical analyses, and wrote the manuscript. RA contributed in statistical analyses and manuscript preparation. MK supervised the study and contributed critically in statistical analyses, interpretation, and manuscript preparation. All authors reviewed and approved the final manuscript.

\section{Ethics approval and consent to participate}

As this study uses publicly available secondary data, so no consent to participate was required by the authors.

\section{Consent for publication}

Not applicable.

\section{Competing interests}

The authors declare that they have no competing interests.

\section{Publisher's Note}

Springer Nature remains neutral with regard to jurisdictional claims in published maps and institutional affiliations.

\begin{abstract}
Author details
${ }^{1}$ Department of Health Care Policy and Management, Graduate School of Comprehensive Human Sciences, University of Tsukuba, Tennoudai, Tsukuba, Ibaraki, Japan. Department of Community and Global Health, Graduate School of Medicine, The University of Tokyo, Tokyo, Japan. ${ }^{3}$ Department of Health Care Policy and Health Economics, Faculty of Medicine, University of Tsukuba, Tennoudai, Tsukuba, Ibaraki, Japan.
\end{abstract}

Received: 22 June 2017 Accepted: 1 February 2018

\section{Published online: 14 February 2018}

\section{References}

1. World Health Organization. Tracking universal health coverage: first global monitoring report. Geneva: World Health Organization; 2015.

2. Carrin G, Evans D, Xu K. Designing health financing policy towards universal coverage. Bull World Health Organ. 2007;85(9):652.

3. World Health Organization. The world health report 2013: research for universal health coverage. Geneva: World Health Organization; 2013.

4. Xu K, Evans DB, Kawabata K, Zeramdini R, Klavus J, Murray CJ. Household catastrophic health expenditure: a multicountry analysis. Lancet. 2003;362:111-7.

5. van Doorslaer E, O'Donnell O, Rannan-Eliya RP, Samanathan A, Adhikari SR, Garg CC, et al. Effect of payments for health care on poverty estimates in 11 countries in Asia: an analysis of household survey data. Lancet. 2006;368:1357-64.

6. United Nations. Sustainable development goals: 17 goals to transform our world. New York: United Nations; 2016. [http://www.un.org/sustainabledevelopment/ sustainable-development-goals/ ]. Accessed on 10 Sept 2016.

7. Xu K, Evans DB, Carrin G, Aguilar-Rivera AM, Musgrove P, Evans T. Protecting households from catastrophic health spending. Health Aff (Millwood). 2007;26(4):972-83.

8. Devadasan N, Criel B, Van Damme W, Ranson K, Van der Stuyft P. Indian community health insurance schemes provide partial protection against catastrophic health expenditure. BMC Health Serv Res. 2007;7(1):1-11.
9. Aji B, Yamamoto SS, Sauerborn R. The economic impact of the insured patients with severe chronic and acute illnesses: a qualitative approach Glob Health Action. 2014;7:22526.

10. Reddy SR, Ross-Degnan D, Zaslavsky AM, Soumerai SB, Wagner AK. Health care payments in the Asia Pacific: validation of five survey measures of economic burden. Int J Equity Health. 2013;12(1):49.

11. World Health Organization. WHO global health expenditure atlas. Geneva: World Health Organization; 2014.

12. Government of Nepal, Department of Health Services. National health insurance policy. Kathmandu: Government of Nepal; 2013.

13. Ministry of Health and Population. Nepal health sector strategy 2015-2020. Kathmandu: Government of Nepal; 2015.

14. Social Health Security Development Committee. Annual report 2072/73. Kathmandu, Nepal: Government of Nepal; 2016.

15. Deutsche Gesellschaft für Internationale Zusammenarbeit. Review of community-based health insurance initiatives in Nepal. Nepal: Deutsche Gesellschaft für Internationale Zusammenarbeit (GIZ) GmbH; 2012.

16. Asian Development Bank. Country poverty analysis (detailed) Nepal. ADB Publications; 2013. https://www.adb.org/countries/nepal/poverty. Accessed 09 Sep 2016.

17. van Doorslaer E, O'Donnell O, Rannan-Eliya RP, Somanathan A, Adhikari SR, Garg CC, et al. Catastrophic payments for health care in Asia. Health Econ. 2007;16(11):1159-84

18. Hotchkiss DR, Rous JJ, Karmacharya K, Sangraula P. Household health expenditures in Nepal: implications for health care financing reform. Health Policy Plan. 1998;13(4):371-83.

19. Adhikari SR, Maskay NM, Sharma BP. Paying for hospital-based care of kalaazar in Nepal: assessing catastrophic, impoverishment and economic consequences. Health Policy Plan. 2009;24(2):129-39.

20. Saito E, Gilmour S, Rahman MM, Gautam GS, Shrestha PK, Shibuya K. Catastrophic household expenditure on health in Nepal: a cross-sectional survey. Bull World Health Organ. 2014;92(10):760-7.

21. Li Y, Wu Q, Xu L, Legge D, Hao Y, Gao L, et al. Factors affecting catastrophic health expenditure and impoverishment from medical expenses in China: policy implications of universal health insurance. Bull World Health Organ. 2012;90(9):664-71.

22. Van Minh H, Kim Phuong NT, Saksena P, James CD, Xu K. Financial burden of household out-of-pocket health expenditure in Viet Nam: findings from the national living standard survey 2002-2010. Soc Sci Med. 2013;96:258-63.

23. Yardim MS, Cilingiroglu N, Yardim N. Catastrophic health expenditure and impoverishment in Turkey. Health Policy. 2010;94(1):26-33.

24. Central Bureau of Statistics. Nepal living standards survey 2010/11: statistical report. Kathmandu: Government of Nepal; 2011.

25. Deaton A, Zaidi S. Guidelines for constructing consumption aggregates for welfare analysis. Living standards measurement study. Working paper no. 135. Washington DC: World Bank; 2002.

26. Wagstaff A, van Doorslaer E. Catastrophe and impoverishment in paying for health care: with applications to Vietnam 1993-1998. Health Econ. 2003;12(11):921-34.

27. Buigut S, Ettarh R, Amendah DD. Catastrophic health expenditure and its determinants in Kenya slum communities. Int J Equity Health. 2015;14:46.

28. Chuma J, Maina T. Catastrophic health care spending and impoverishment in Kenya. BMC Health Serv Res. 2012;12:413.

29. Su T, Kouyate B, Flessa S. Catastrophic household expenditure for health care in a low-income society: a study from Nouna District, Burkina Faso. Bull World Health Organ. 2006;84(1):21-7.

30. Adisa O. Investigating determinants of catastrophic health spending among poorly insured elderly households in urban Nigeria. Int J Equity Health. 2015;14(1):79.

31. Gotsadze G, Zoidze A, Rukhadze N. Household catastrophic health expenditure: evidence from Georgia and its policy implications. BMC Health Serv Res. 2009;9:69.

32. Brinda EM, Andres AR, Enemark U. Correlates of out-of-pocket and catastrophic health expenditures in Tanzania: results from a national household survey. BMC Int Health Hum Rights. 2014;14:5.

33. Rahman MM, Gilmour S, Saito E, Sultana P, Shibuya K. Health-related financial catastrophe, inequality and chronic illness in Bangladesh. PLoS One. 2013;8(2):e56873.

34. Bursac Z, Gauss CH, Williams DK, Hosmer DW. Purposeful selection of variables in logistic regression. Source Code Biol Med. 2008;3(1):1-8

35. Knaul FM, Arreola-Ornelas H, Mendez-Carniado O, Bryson-Cahn C, Barofsky J, Maguire $\mathrm{R}$, et al. Evidence is good for your health system: policy reform to remedy catastrophic and impoverishing health spending in Mexico. Lancet. 2006;368(9549):1828-41. 
36. Sauerborn R, Adams A, Hien M. Household strategies to cope with the economic costs of illness. Soc Sci Med. 1996;43(3):291-301.

37. Grossman M. The demand for health: a theoretical and empirical investigation. New York: Columbia University Press; 1972

38. Marmot M, Friel S, Bell R, Houweling TAJ, Taylor S. Closing the gap in a generation: health equity through action on the social determinants of health. Lancet. 2008;372(9650):1661-9.

39. Kondo M, McPake B. Making choices between prepayment and user charges in Zambia. What are the results for equity? Health Econ. 2007; 16(12):1371-87.

40. Pal R. Analysing catastrophic OOP health expenditure in India: concepts, determinants and policy implications. India: Indira Gandhi Institute of Development Research; 2010.

Submit your next manuscript to BioMed Central and we will help you at every step:

- We accept pre-submission inquiries

- Our selector tool helps you to find the most relevant journal

- We provide round the clock customer support

- Convenient online submission

- Thorough peer review

- Inclusion in PubMed and all major indexing services

- Maximum visibility for your research

Submit your manuscript at www.biomedcentral.com/submit
Biomed Central 